\title{
Incidence and Risk Factors for Ventilator-Associated Pneumonia in Kathmandu University Hospital
}

\section{Ranjit S, Bhattarai B}

Department of Anaesthesiology

Dhulikhel Hospital - Kathmandu University Hospital, Kavre, Nepal

\section{Corresponding author}

Dr. Sangina Ranjit

Department of Anaesthesiology

Kathmandu University School of Medical Sciences, Dhulikhel Hospital

Email: sanginaranjit@yahoo.co.uk

\section{Citation}

Ranjit S, Bhattarai B. Incidence and risk factors for ventilator-associated pneumonia in Kathmandu University Hospital. Kathmandu Univ Med J 2011;33(1)28-31.

\section{ABSTRACT}

\section{Background}

Ventilator associated pneumonia is a major cause of morbidity in the intensive care unit. Difficulties in identification of the risk factors, in diagnosing and in prevention, have intensified the problem.

\section{Objectives}

To measure the incidence of ventilator associated pneumonia in intensive care unit and to identify the risk factors associated.

\section{Methods}

A prospective observational cohort study of 69 patients who were mechanically ventilated for more than 48 hours were evaluated to find out the development of nosocomial pneumonia and presence or absence of risk factors. Data were subjected to univariate analysis using chi-square and t-test. Level of significance was set at 0.05 .

\section{Results}

Twenty two (31.88\%) out of 69 patients developed ventilator associated pneumonia, majority of them between four days to 14 days. Reintubation, invasive lines, $\mathrm{H}_{2}$ blockers and low $\mathrm{PaO}_{2} / \mathrm{FiO}_{2}$ were identified as major risk factors in our study. Enteral feeding via nasogastric tube and use of steroids was not associated with development of ventilator associated pneumonia. The patients with ventilator associated pneumonia had significantly longer duration of mechanical ventilation (18.88 \pm 7.7 days vs $7.36 \pm 4.19$ days) and stay ( $29 \pm 17.8$ days vs $9.22 \pm 5.14$ days). The morality was similar for both the groups with or without ventilator associated pneumonia.

\section{Conclusion}

The incidence of ventilator pneumonia is high. Patients requiring prolonged ventilation, re-intubation, more invasive lines and $\mathrm{H}_{2}$ blockers, are at high risk and need special attention towards prevention.

\section{KEY WORDS}

nosocomial infection, prolonged mechanical ventilation, risk factors, ventilator associated pneumonia

\section{INTRODUCTION}

Nosocomial infections are common in the Intensive Care Unit (ICU) and ventilator associated pneumonia (VAP) represents second most common nosocomial infection in the ICU. ${ }^{1}$ Ventilator associated pneumonia stands as an important cause of hospital morbidity and mortality. ${ }^{2,3}$ Intubated patients are at risk of developing VAP and the incidence increases with the duration of ventilator support. The cumulative risk is estimated to be $1 \%$ - 3\% per day of mechanical ventilation. ${ }^{4}$ The incidence varies depending on criteria used for diagnosis, the type of ICU, and hospital resources or study population. Data from developing countries reveal an incidence which ranges from $15.87 \%$ $30.67 \%$. $^{5}$
During prolonged mechanical ventilation, the oropharynx, nasopharynx, sinuses and dentition become colonized with pathogens which with secretions get pooled into the subglottic space. These then make their way to the lower respiratory tract via micro-leak in the endotracheal tube cuff, thus causing pneumonia. In addition, the endotracheal tube holds the vocal cords open, further allowing access to the aspirate. Re-intubation, higher APACHE score, multiple invasive lines, immunosuppression, enteral feeding via nasogastric tube, $\mathrm{H}_{2}$ blockers, antacids, supine head position, paralytic agents and sedation are all independent risk factors for VAP. ${ }^{6}$ This prospective study was conducted in a five beded ICU in Dhulikhel Hospital, Kathmandu 
University hospital over a period of two and a half years to define the magnitude of this problem by finding out the incidence, common organisms involved and the associated risk factors.

\section{METHODS}

This prospective, observational cohortstudy was undertaken after obtaining approval from hospital Institution Research Committee and written, informed consent form the patients' relatives before putting on ventilator. The study took place in a five beded adult ICU of Dhulikhel Hospital, a 340 beded University Hospital. Over the duration of two and a half years, starting from January 2008 till July 2010, 98 patients were intubated for mechanical ventilation. Out of them, 69 patients were enrolled in the study. Patients who expired or left against medical advice before 48 hours of ventilation were excluded from the study. Those who were admitted to ICU with diagnosis of pneumonia or had any infiltrations in the chest X-ray at the time of ICU admission were also excluded.

Baseline characteristics which included age, gender, admitting diagnosis, indication for mechanical ventilation, and oxygenation ( $\mathrm{PaO} 2 / \mathrm{FiO} 2)$ prior to onset of VAP were noted. These patients were prospectively followed for development of pneumonia. VAP was diagnosed as per CDC criteria. $^{7}$

Patients who are mechanically ventilated for more than 48 hours, with occurrence of new and persistent infiltration in the chest roentgen, together with any two of the following:

1. Fever, defined as temperature $>38^{\circ} \mathrm{C}$

2. Leukocytosis, defined as total leukocyte count $>10 \times 10^{3}$

\section{Purulent tracheal aspirate}

Chest $X$ ray was done at the time admission and repeated every day. This diagnosis was confirmed by the presence of organisms on culture of tracheal aspirate. The tracheal aspirates were sent for gram staining and microbial analysis - culture and antibiotic sensitivity done routinely after 48 hours of mechanical ventilation. This was repeated at 48 hours if initially negative. The organisms detected on culture of tracheal aspirate were charted for the purpose of identifying the causative agent. Antibiotics were changed as per sensitivity pattern. Total leukocyte count was done as indicated by the admitting diagnosis or routinely at 48 hours or as indicated by chest X-ray findings.

The patients who developed VAP or met the above criteria within 96 hours of mechanical ventilation were categorized as early onset VAP and those who developed the same after this time period were categorized as late-onset VAP.

All the patients were managed with routine strategies for mechanical ventilation: semi-recombinant position at $45^{\circ}$, sedation and analgesia with midazolam and morphine/ fentanyl titrated to tube tolerance, chlorhexidine oral care, deep vein thrombosis prophylaxis, active and passive chest physiotherapy by the physiotherapist. None of the patients were paralyzed.

The incidence of VAP was noted and each surrogate variable was analyzed. The surrogate variables that included risk factors for VAP were re-intubation, peptic ulcer prophylaxis, enteral feeding, invasive lines, use of ionotrops, low initial $\mathrm{PaO}_{2} / \mathrm{FiO}_{2}$ ratio and steroid use. Each of these variables were noted and compared between 2 groups - VAP and non-VAP. Although called for, the APACHE score was not done in our study as it was not feasible for all the patients at our center to bear the cost of all the investigations necessary. Investigations were limited to the very essential ones due to cost constraints.

The outcome of the disease was measured by length of ICU stay and duration of mechanical ventilation. The data was entered and tabulated in Microsoft Excel. The statistics were analyzed using website: http://www.graphpad.com. The obtained data were subjected to the univariate analysis using the chi-square test. Comparison of data comprising mean \pm SD was done with the help of t-test. P-values less than 0.05 were considered as significant. We included the risk factors for chi-square test, and age and duration of mechanical ventilation/ ICU stay for t-test (as it contains data comprising of mean +/- SD).

\section{RESULTS}

During the period of study, 98 patients were mechanically ventilated. Out of them, 8 were with initial diagnosis of pneumonia, 6 had left against medical advice and 15 had expired before 48 hours. These patients were excluded from the study. Sixty nine patients were enrolled in the study. Out of them, 28 (40.58\%) were male and 41 (59.42\%) were female (Table 1$)$. The mean age of the patients was $33.66 \pm 18.84$. Among the patients, 22 (31.88\%) developed VAP. Mean $\mathrm{PaO} 2 / \mathrm{FiO}_{2}$ was 211 for VAP and 286 for non VAP patients.

Table 1. Demographic data of the study patients

\begin{tabular}{lcccc} 
& VAP & Non-VAP & Total & p-value \\
\hline Male & 10 & 18 & 28 & 0.57 \\
Female & 12 & 29 & 41 & \\
Age (mean \pm SD y) & $32.69 \pm 23.75$ & $43.33 \pm 25.37$ & - & 0.10
\end{tabular}

The clinical spectrum of the study patients are demonstrated in table 2. The most frequent of the cases were organophosphate poisoning. Other frequent cases were 12 patients post abdominal surgery and 13 patients with septicemia. Higher incidence of VAP occurred in poisoning, post laparotomy and COPD. 
Table 2. Clinical spectrum of different disease conditions.

\begin{tabular}{lcccc} 
Admission diagnosis & VAP & $\begin{array}{c}\text { Non- } \\
\text { VAP }\end{array}$ & Total & Percentage \\
\hline Poisoning & 7 & 16 & 23 & 30.43 \\
Abdominal surgery & 4 & 8 & 12 & 33.33 \\
$\begin{array}{l}\text { Septicemia } \\
\text { COPD }\end{array}$ & 3 & 10 & 13 & 23.07 \\
$\begin{array}{l}\text { Neurological } \\
\text { (meningitis, encephalitis, }\end{array}$ & 4 & 4 & 8 & 50 \\
$\begin{array}{l}\text { GBS, stroke) } \\
\text { Trauma }\end{array}$ & 2 & 5 & 6 & - \\
$\begin{array}{l}\text { Metabolic disorders / } \\
\text { dyselectrolytemia }\end{array}$ & 1 & 3 & 4 & - \\
$\begin{array}{l}\text { Pulmonary embolism } \\
\text { Fat embolism }\end{array}$ & 0 & 1 & & - \\
Pneumothorax & 0 & 1 & & - \\
\hline
\end{tabular}

The total number exceeds the actual total due to some patients with multiple diagnosis.

COPD=Chronic Obstructive Pulmonary Disease, GBS=Guillain Barre Syndrome

Patients requiring inotropes or vasopressors, invasive lines had significantly higher incidence of VAP. Use of peptic ulcer prophylaxis, $\mathrm{H}_{2}$ blockers was also significantly associated with VAP. Development of VAP was similarly high in patients who were initially hypoxic $-\mathrm{PaO}_{2} / \mathrm{FiO}_{2}$ ratio $<200$. Out of 18 patients who required re-intubation, 12 of them developed VAP, which was highly significant $(P<0.001)$. The incidence of VAP was significantly less in enterally fed patients. Out of 47 enterally fed patients, only 19 developed VAP and this was statistically significant. Use of steroid did not result in significant increase in incidence of VAP in our study cohort.

Table 3. Risk factors associated with VAP

\begin{tabular}{|c|c|c|c|c|}
\hline Risk factors & Total & VAP & Non-VAP & $p$-value \\
\hline $\begin{array}{l}\text { lonotrops/vaso- } \\
\text { pressors }\end{array}$ & 25 & 13 & 12 & 0.006 \\
\hline CVP/arterial lines & 41 & 21 & 20 & 0.001 \\
\hline H2 blocker & 24 & 12 & 12 & 0.018 \\
\hline $\begin{array}{l}\mathrm{PaO}_{2} / \mathrm{FiO}_{2}<200 \text { on } \\
\text { day } 2\end{array}$ & 19 & 10 & 9 & 0.023 \\
\hline Enteral feed & 47 & 19 & 28 & 0.026 \\
\hline Steroids & 21 & 7 & 14 & 0.86 \\
\hline Re-intubation & 18 & 12 & 6 & $<0.001$ \\
\hline
\end{tabular}

$\mathrm{CVP}=$ central venous pressure, $\mathrm{H}_{2}$ blockers $=$ histamine receptor 2 blocker, $\mathrm{PaO}_{2} / \mathrm{FiO}_{2}=$ arterial partial pressure of oxygen/fraction of oxygen in inspired air.

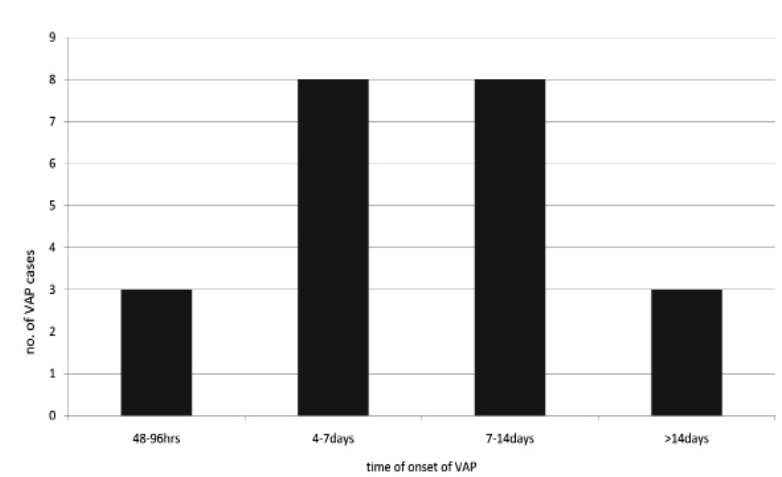

Figure 1. Shows the onset of VAP. Only 3 out of 69 developed early onset VAP. Most of the VAP occurred between 4 days to 2 weeks.

The causative organisms isolated from culture of tracheal aspirate are shown in Table 4 . Out of 32 cultures from 22 VAP patients, the most common organism was found to be Acinetobacter bumanii. Four culture reports revealed more than one organism. Majority of microbes were gram negative. Klebsiella sp. was commonly found in early-onset pneumonia. No cases had methicillin resistant Staphylococcus aureus.

\section{Table 4. Causative organisms of VAP}

$\begin{array}{lcc}\text { Organism } & \text { Early onset } & \text { Late onset } \\ \text { Staphylococcus aureus (MSSA) } & 2 & - \\ \text { Klebsiella sp. } & 5 & 4 \\ \text { Pseudomonas aeroginosa } & - & 6 \\ \text { Acenobacter baumanii } & - & 11 \\ \text { E.coli } & - & 5 \\ \text { Enterococcus sp } & - & 4\end{array}$

Out of 22 patients who developed VAP, 13 (59.1\%) required tracheostomy indicated for prolonged need of mechanical ventilation (Table 5). The duration of mechanical ventilation for the VAP group was significantly high $(p<0.001)$. Similarly, the VAP group also had significantly longer duration of ICU stay $(p=0.006)$. Crude mortality in the study cohort was $21.9 \%$. The mortality rate for VAP group was $22.2 \%$ and for non-VAP was $21.74 \%$ with no significant difference between the two.

Table 5. Outcome of mechanically ventilated patients

$\begin{array}{lcccc}\text { Outcome } & \text { Total } & \text { VAP } & \text { Non-VAP } & p \text {-value } \\ \text { Tracheostomy } & 13 & 10 & 3 & <0.001 \\ \begin{array}{l}\text { Duration of } \\ \text { MV }(\text { mean } \pm S D \text { d) }\end{array} & - & 18.88 \pm 7.7 & 7.36 \pm 4.19 & <0.001 \\ \begin{array}{l}\text { Duration of ICU } \\ \text { stay (mean } \pm S D \text { d) }\end{array} & - & 29 \pm 17.88 & 9.22 \pm 5.14 & 0.006 \\ \text { MV=mechanical ventilation } & & & \end{array}$




\section{DISCUSSION}

VAP stands as a co ts were found to be age $>70$, reintubation, intraoperative inotropic support, transfusion, days of mechanical ventilation, emergent surgery. ${ }^{12}$ Use of steroids, however, did not seem to be a risk factor for development of VAP in the present study, though some studies identified this as a risk factor. ${ }^{12}$

Though enteral feed via nasogastric tube has been stated as a risk factor due to increased gastric $\mathrm{pH}$, volume and regurgitation, it may have improved the nutritional status, decreased gut translocation and prevented VAP in our patients. ${ }^{14,15}$ Intermittent feed, semi- recombinant position at $45^{\circ}$, avoidance of gastric over distension and use of prokinetics when required, has decreased the incidence of VAP in some studies. ${ }^{16,17}$ Similar finding was observed in our study.

Tracheostomy has also been stated as a risk factor by some studies. ${ }^{8,10}$ However, some studies state that early and planned tracheostomy protects mechanically ventilated patients from VAP. ${ }^{9}$ Our patients rather had late tracheostomies between 7-14 days. So this was studied as an outcome of VAP and need of prolonged mechanical ventilation.

\section{REFERENCES}

1. Jarvis WR, Edward JR, Culver DH. Nosocomial infection rates in ICUs in the United States: National Nosocomial Infection Surviellance System. Am J Med Br 1991; 91:1855-15.

2. Bowton DL et al. Nasocomial pneumonia in the ICU: year 2000 and beyond. Chest 1999;115(3): 28S-33S.

3. Mc Eachem R, Campbell GD Jr. Hospital acquired pneumonia: epidemiology, etiology and treatment. Infect Disease Clinics of North America 1998; 12(3): 761-779.

4. George DL. Epidemiology of nosocomial pneumonia in MICU. Med Clin Chest Med 1995;16:29-44.

5. Joseph NM, Sistla S, Dutta TM et al,.Ventilator-associated pneumonia in a tertiary care hospital in India: incidence and risk factors. J Infect Dev Ctries 2009; 3(10):771-777.

6. Chastre J, Fagon J. ventilator associated pneumonia. Am J Resp Crit Care Med 2002; 165: 887-903.

7. Klompas M, Kleinman K, Platt R. Development of an Algorithm for Surveillance of Ventilator-associated pneumonia with electronic data and comparision of Algorithm results with clinician diagnoses. Infect Control Hosp Epidemiol 2008; 29(1):31-37.

8. Apostolopouou E, Bakakos P, Katastaras T, et al. Incidence and Risk Factors for Ventilator-Associated Peumonia in 4 Multidisciplinary Intensive Care Units in Athens, Greece. Respiratory Care 2003; 48(7): 681-688.

9. Panwar R, Vidya S, Alaka K. incidence, clinical outcome, and risk stratification of ventilator-associated pneumonia-a prospective cohort study. Indian J Crit Care Med 2005; 9(4): 211-216.

10. Ibrahim EH, Tracy L, Hill C, et al. The occurrence of ventilatorassociated pneumonia in a community hospital: risk factors and clinical outcomes. Chest 2001; 120(2): 555-561.

11. Gadani $H$, Vyas A, Kar AK. A study of ventilator-associated pneumonia: Incidence, outcome, risk factors and measures to be taken for prevention. Indian Journal of Anaesthesia 2010; 54(6): 535-540.
Although morbidity and ICU stay was prolonged in our patients with VAP, the mortality was similar for both groups. Other studies ${ }^{18}$ also reported similar outcomes.

Gram negative bacteria, Pseudomonas aeruginosa and Acinetobacter baumanii are commonly associated with late onset VAP. ${ }^{19,} 20$ Our ICU patients had Acinetobacter sp. as the most common causative microbe.

In our study, we used a qualitative study of tracheal aspirate (TA) rather than quantitative bronchioalveolar lavage (BAL) because of its ease, cost effectiveness and equivalence in sensitivity. ${ }^{21,22}$ A study by Daren Heyland had concluded that similar outcomes and use of antibiotics result whether the diagnosis of VAP is made by TA or BAL. ${ }^{21}$

\section{CONCLUSION}

The incidence of ventilator-associated pneumonia is high in our setting. Gram negative bacteria causing late-onset VAP is common. Patients who require invasive lines, inotropes, re-intubation, $\mathrm{H}_{2}$ blockers, are at high risk. Requirement of mechanical ventilation for more than four days increases the risk. These patients need special attention towards preventive measures such as hygiene, proper weaning protocol, early and planned tracheostomy.

12. Hortal J,Giannella M, Perez MJ, et al. Incidence and risk factors for ventilator-associated pneumonia after major cardiac surgery. Intensive Care Med 2009; 35(9): 1518-25.

13. Pawar M, Mehta $Y$, Khurana P. Ventilator-associated pneumonia: incidence, risk factors, outcome and microbiology. J Cardiothoracic Vasc Anaesth 2003; 17(1): 22-28.

14. Bonten MJ, Gillard CA,van der Hulst $\mathrm{R}$ et al. Intermittent enteral feeding: the influence on respiratory and digestive colonization in mechanically ventilated intensive care unit patients. American Journal of Respiratory and Critical Care Medicine 1996; 154: 394-9.

15. Young PJ, Ridley SA. Ventilator-associated pneumonia - diagnosis, pathogenesis and prevention. Anaesthesia 1999; 54: 1183-1197.

16. Gaucouin A, Barbarot N, Camus C.Late onset Ventilator-associated pneumonia in non-trauma intensive care patients. Anesth Analg 2009; 109: 1584-90.

17. Grahlich L, Kichian K, Pinilla J. Does enteral nutrition compared to parenteral nutrition result in better outcomes in critically ill adult patients? A systematic review of the literature. Nutrition 2004; 20 : 843-848.

18. Wilhelmina G, Maroeska M, Marc J M. Ventilator-associated pneumonia and mortality: A systematic review of observational studies. Critical Care Medicine 2009; 37(10): 2709-18.

19. Joseph NM, Sistla S, Dutta T et al. ventilator-associated pneumonia in a tertiary care hospital in India: role of multi-drug resistant pathogens.J Infect Dev Ctries 2010;4(4):218-225.

20. Akca O, Koltka K, Uzel S. Risk Factors for early-onset, ventilator associated pneumonia in critical care patients. Anaesthesiology 2000; 93:638-45.

21. Daren Heyland, Deborah Cook, Peter Dodek, et al.A randomized trial of diagnostic techniques for ventilator-associated pneumonia. N Eng J Med 2006; 335: 2619-2630.

22. Shorr AF, Sherner JH, Jackson $W L$, et al. Invasive approaches to the diagnosis of ventilator-associated pneumonia: A meta-analysis. Critical Care Medicine 2005; 33(1): 46-53. 